\title{
Risk factor for steatorrhea in pediatric chronic pancreatitis patients
}

\author{
Lu Hao ${ }^{1,2+}$, Teng Wang ${ }^{2,3+}$, Lin He ${ }^{2 \dagger}$, Ya-Wei Bi ${ }^{2}$, Di Zhang ${ }^{2}$, Xiang-Peng Zeng ${ }^{2}$, Lei Xin ${ }^{2,3}$, Jun Pan ${ }^{2}$, Dan Wang ${ }^{2}$, \\ Jun-Tao Ji ${ }^{3}$, Ting-Ting Du², Jin-Huan Lin², Li-Sheng Wang ${ }^{4}$, Wen-Bin Zou², Hui Chen ${ }^{2,3}$, Ting Xie ${ }^{5}$, Hong-Lei Guo ${ }^{2}$, \\ Bai-Rong Liं ${ }^{6}$, Zhuan Liao ${ }^{2,3}$, Zheng-Lei $\mathrm{Xu}^{4^{*}}$, Zhao-Shen $\mathrm{Li}^{2,3^{*}} \mathrm{D}$ and Liang-Hao Hu $\mathrm{u}^{2,3^{*}}$
}

\begin{abstract}
Background: Pediatric patients always suffer from chronic pancreatitis (CP), especially those with steatorrhea. This study aimed to identify the incidence of and risk factors for steatorrhea in pediatric CP. To our best knowledge, there is no pediatric study to document the natural history of steatorrhea in CP.

Methods: CP patients admitted to our center from January 2000 to December 2013 were enrolled. Patients were assigned to the pediatric ( $<18$ years old) and adult group according to their age at onset of CP. Cumulative rates of steatorrhea in both groups were calculated. Risk factors for both groups were identified, respectively.

Results: The median follow-up duration for the whole cohort was 7.6 years. In a total of 2153 patients, 13.5\% of them were pediatrics. The mean age at the onset and the diagnosis of CP in pediatrics were 11.622 and 19.727 , respectively. Steatorrhea was detected in 46 patients $(46 / 291,15.8 \%)$ in the pediatric group and in 447 patients $(447 / 1862,24.0 \%)$ in the adult group. Age at the onset of CP (hazard ratio [HR], 1.121), diabetes mellitus (DM, HR, 51.140), and severe acute pancreatitis (SAP, $H R$, 13.946) was identified risk factor for steatorrhea in the pediatric group.

Conclusions: Age at the onset of CP, DM and SAP were identified risk factors for the development of steatorrhea in pediatric CP patients. The high-risk populations were suggested to be followed up closely. They may benefit from a full adequate pancreatic exocrine replacement therapy.
\end{abstract}

Keywords: Chronic pancreatitis, Pediatric, Steatorrhea, Risk factors

\section{Background}

Chronic pancreatitis (CP) is a rare disease in children. Recent studies have estimated that the incidence of $\mathrm{CP}$ in children is approximately 0.5 per 100,000 per year [13]. The essence of this disease is the destruction of the organ's parenchyma by a progressive inflammation process [4]. Pediatric patients with CP always suffer from the severe pain and progressive loss of both exocrine and endocrine function. The irreversible damage of

\footnotetext{
*Correspondence: 78249073@qq.com; zhaoshen-li@hotmail.com; lianghaohu@hotmail.com

${ }^{\dagger}$ Lu Hao, Teng Wang and Lin He contributed equally to this work.

${ }^{4}$ Department of Gastroenterology, The Second Clinical Medical College

(Shenzhen People's Hospital), Jinan University, Guangdong, China

${ }^{2}$ Department of Gastroenterology, Gongli Hospital, The Second Military

Medical University, Shanghai, China

Full list of author information is available at the end of the article
}

pancreatic exocrine function in $\mathrm{CP}$ patients will result in pancreatic enzyme insufficiency (PEI). Severe PEI, or pancreatic exocrine failure, is considered to be clinical steatorrhea, and is a common adverse event of CP. PEI usually manifests as malnutrition, which resulting in vitamin and micronutrient deficiency and weight loss [5, $6]$, and is at risk of developing premature atherosclerosis, cardiovascular events, osteoporosis, fracture, immune deficiency, and infection [7-9]. PEI is extremely harmful for children. It is well known that malnutrition caused by reduced dietary intake and malabsorption delays the growth and development of these children [10], which also seriously impairs their childhood and mental health [11].

However, in CP patients, a significant proportion of PEI did not show dominant steatorrhea. Functional testing directly for PEI is difficult in clinical practice.

(c) The Author(s). 2018 Open Access This article is distributed under the terms of the Creative Commons Attribution 4.0 International License (http://creativecommons.org/licenses/by/4.0/), which permits unrestricted use, distribution, and 
Therefore, patients with PEI were rarely confirmed at the early stage [12]. The detection of risk factors for PEI may be clinical important for pediatrics. Pancreatic exocrine replacement therapy (PERT) was recommended in pediatric CP patients according to Australasian Pancreatic Club recommendations [13], but it has a lower level of evidence, and more clinical data was needed. To our best knowledge, there is no pediatric study to document the natural history of steatorrhea in CP. Thus, we aimed to compare the profile of pediatric and adult $\mathrm{CP}$ patients. This study was based on a retrospective-prospective cohort of $2153 \mathrm{CP}$ patients with a long duration of follow-up after the onset of CP. We compared the natural history, etiology, complications, and treatment of CP in pediatrics and adults. We also determined the incidence of steatorrhea, and identified the risk factors for this complication in pediatric and adult $\mathrm{CP}$ patients, respectively.

\section{Methods}

\section{Patients and database}

The subjects of this study were CP patients hospitalized in Shanghai Changhai Hospital from January 2000 to December 2013. From January 2000 to December 2004, a retrospective collection of patient data was made according to the medical record system, telephone, mail and e-mail follow-up. In order to follow up the patients with $\mathrm{CP}$ and facilitate the study of CP. The database system of CP (version 2.1, YINMA Information Technology Company, Shanghai, China) has been established in the Department of Gastroenterology of Changhai Hospital since January 2005 to collect the medical records of patients with CP. Data collected from January 2005 to December 2013 were prospectively collected [12, 1423]. All patient information is first recorded in a paper-based case report form and then entered into an electronic document. The information collected includes basic information of patients, etiological characteristics (drinking, smoking, anatomic abnormalities, family history), natural course of CP (onset date, onset symptoms, diagnosis date, onset date of pain, pain classification, diagnosis date and treatment history of stones, diabetes mellitus, fatty diarrhea, pseudocysts, common bile duct stenosis); treatment strategy (conservative treatment, endoscopic treatment, surgical treatment).

The database system will remind researchers to notify patients for examination. Except for the examination

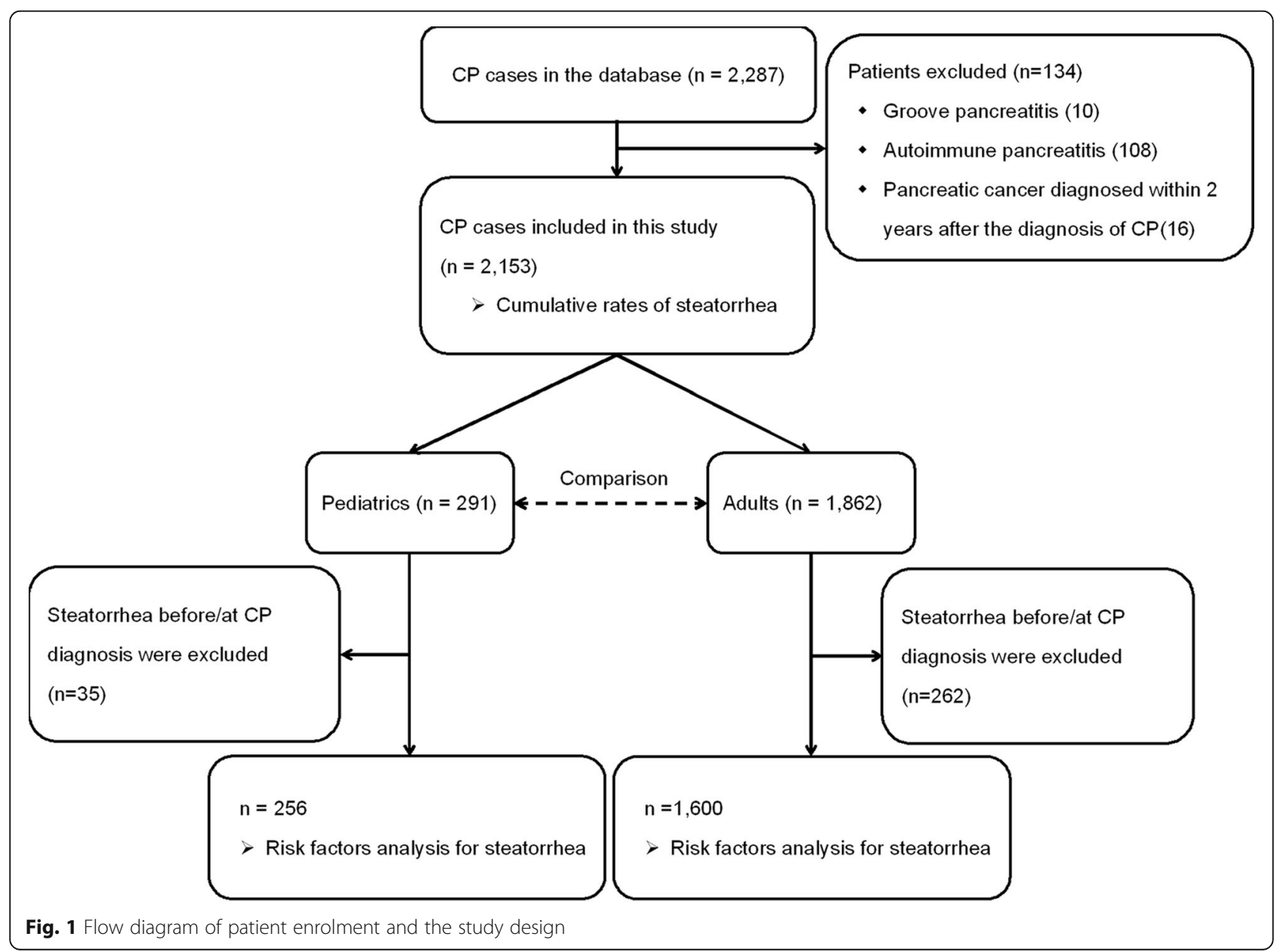


Table 1 General Characteristics of 2153 patients with CP

\begin{tabular}{|c|c|c|c|c|}
\hline Items & $\begin{array}{l}\text { Overall }(n=2153) \\
\mathrm{n}(\%)\end{array}$ & $\begin{array}{l}\text { Pediatrics }(n=291) \\
\text { n (\%) }\end{array}$ & $\begin{array}{l}\text { Adults }(n=1862) \\
\mathrm{n}(\%)\end{array}$ & $P$ value \\
\hline Gender (male) & $1486(69.0 \%)$ & $143(49.1 \%)$ & $1343(72.1 \%)$ & $<0.001$ \\
\hline Age at the onset of $C P, y^{a}$ & $38.230 \pm 16.606$ & $11.622 \pm 4.652$ & $42.388 \pm 13.692$ & $<0.001$ \\
\hline Age at the diagnosis of $\mathrm{CP}, \mathrm{y}^{\mathrm{a}}$ & $43.077 \pm 15.548$ & $19.727 \pm 8.953$ & $46.727 \pm 12.980$ & $<0.001$ \\
\hline Smoking history & $723(33.6 \%)$ & $16(5.5 \%)$ & 707 (38.0\%) & $<0.001$ \\
\hline Alcohol consumption & - & - & - & $<0.001$ \\
\hline $0 \mathrm{~g} / \mathrm{d}$ & $1426(66.2 \%)$ & $272(93.5 \%)$ & $1154(62.0 \%)$ & - \\
\hline $0-20 \mathrm{~g} / \mathrm{d}$ & $70(3.3 \%)$ & $8(2.7 \%)$ & $62(3.3 \%)$ & - \\
\hline $20-80 \mathrm{~g} / \mathrm{d}$ & 237 (11.0\%) & $8(2.7 \%)$ & $229(12.3 \%)$ & - \\
\hline$>80 \mathrm{~g} / \mathrm{d}$ & 420 (19.5\%) & $3(1.0 \%)$ & 417 (22.4\%) & - \\
\hline Body mass index ${ }^{a}$ & $20.894 \pm 3.354$ & $19.380 \pm 3.362$ & $24.696 \pm 88.765$ & 0.338 \\
\hline Etiology & - & - & - & $<0.001$ \\
\hline ICP & $1633(75.8 \%)$ & $248(85.2 \%)$ & $1385(74.4 \%)$ & - \\
\hline $\mathrm{ACP}$ & $404(18.8 \%)$ & $2(0.7 \%)$ & $402(21.6 \%)$ & - \\
\hline Abnormal anatomy of pancreatic duct & $64(3.0 \%)$ & $24(8.2 \%)$ & $40(2.1 \%)$ & - \\
\hline $\mathrm{HCP}$ & $30(1.4 \%)$ & $12(4.1 \%)$ & $18(1.0 \%)$ & - \\
\hline Post-traumatic CP & $10(0.5 \%)$ & $3(1.0 \%)$ & $7(0.4 \%)$ & - \\
\hline Hyperlipidemic CP & $12(0.6 \%)$ & $2(0.7 \%)$ & $10(0.5 \%)$ & - \\
\hline Initial manifestations & - & - & - & $<0.001$ \\
\hline Abdominal pain & $1796(83.4 \%)$ & $280(96.2 \%)$ & $1516(81.4 \%)$ & - \\
\hline Endocrine/Exocrine dysfunction & $218(10.1 \%)$ & $9(3.1 \%)$ & $209(11.2 \%)$ & - \\
\hline Others & $139(6.5 \%)$ & $2(0.7 \%)$ & $137(7.4 \%)$ & - \\
\hline Pancreatic stones ${ }^{b}$ & $1627(75.6 \%)$ & $269(92.4 \%)$ & $1358(72.9 \%)$ & $<0.001$ \\
\hline Age at pancreatic stones diagnosis & $41.415 \pm 15.323$ & $20.443 \pm 8.547$ & $45.569 \pm 12.746$ & $<0.001$ \\
\hline Time between onset and pancreatic stone & $5.762 \pm 7.144$ & $8.829 \pm 9.174$ & $5.154 \pm 6.504$ & $<0.001$ \\
\hline DM & $616(28.6 \%)$ & $38(13.1 \%)$ & $578(31.0 \%)$ & $<0.001$ \\
\hline Age at DM diagnosis $^{\mathrm{a}}$ & $45.848 \pm 11.812$ & $28.578 \pm 11.965$ & $46.984 \pm 10.890$ & $<0.001$ \\
\hline Time between onset and $\mathrm{DM}^{\mathrm{a}}$ & $5.136 \pm 7.276$ & $16.617 \pm 13.447$ & $4.381 \pm 5.964$ & $<0.001$ \\
\hline Steatorrhea & $493(22.9 \%)$ & $46(15.8 \%)$ & $447(24.0 \%)$ & 0.002 \\
\hline Age at steatorrhea diagnosis ${ }^{a}$ & $42.563 \pm 12.555$ & $25.880 \pm 9.358$ & $44.279 \pm 11.549$ & $<0.001$ \\
\hline Time between onset and steatorrhea ${ }^{a}$ & $5.245 \pm 8.485$ & $13.929 \pm 10.562$ & $4.351 \pm 7.719$ & $<0.001$ \\
\hline Pancreatic pseudocyst & $350(16.3 \%)$ & $30(10.3 \%)$ & $320(17.2 \%)$ & 0.003 \\
\hline Age at pancreatic pseudocyst diagnosis ${ }^{\mathrm{a}}$ & $45.776 \pm 15.077$ & $16.232 \pm 7.210$ & $48.589 \pm 12.365$ & $<0.001$ \\
\hline Time between onset and pancreatic pseudocyst $\mathrm{t}^{\mathrm{a}}$ & $4.989 \pm 6.954$ & $5.640 \pm 5.828$ & $4.927 \pm 7.058$ & 0.605 \\
\hline Biliary stricture & $340(15.8 \%)$ & $19(6.5 \%)$ & $321(17.2 \%)$ & $<0.001$ \\
\hline Age at biliary stricture diagnosis ${ }^{a}$ & $51.218 \pm 13.169$ & $31.548 \pm 13.686$ & $52.382 \pm 12.200$ & $<0.001$ \\
\hline Time between onset and biliary stricture ${ }^{a}$ & $5.592 \pm 8.637$ & $21.197 \pm 17.565$ & $4.668 \pm 6.809$ & 0.001 \\
\hline Pancreatic cancer & $21(1.0 \%)$ & $1(0.3 \%)$ & $20(1.1 \%)$ & 0.238 \\
\hline Death & $70(3.3 \%)$ & $2(0.7 \%)$ & $68(3.7 \%)$ & 0.008 \\
\hline Morphology of MPD & - & - & - & $<0.001$ \\
\hline Pancreatic stone alone & $590(27.4 \%)$ & $95(32.6 \%)$ & $495(26.6 \%)$ & - \\
\hline MPD stenosis alone & $598(27.8 \%)$ & $57(19.6 \%)$ & $541(29.1 \%)$ & - \\
\hline MPD stenosis and stone & $728(33.8 \%)$ & $128(44.0 \%)$ & $600(32.2 \%)$ & - \\
\hline Complex pathologic changes & $237(11.0 \%)$ & $11(3.8 \%)$ & $226(12.1 \%)$ & - \\
\hline
\end{tabular}


Table 1 General Characteristics of 2153 patients with CP (Continued)

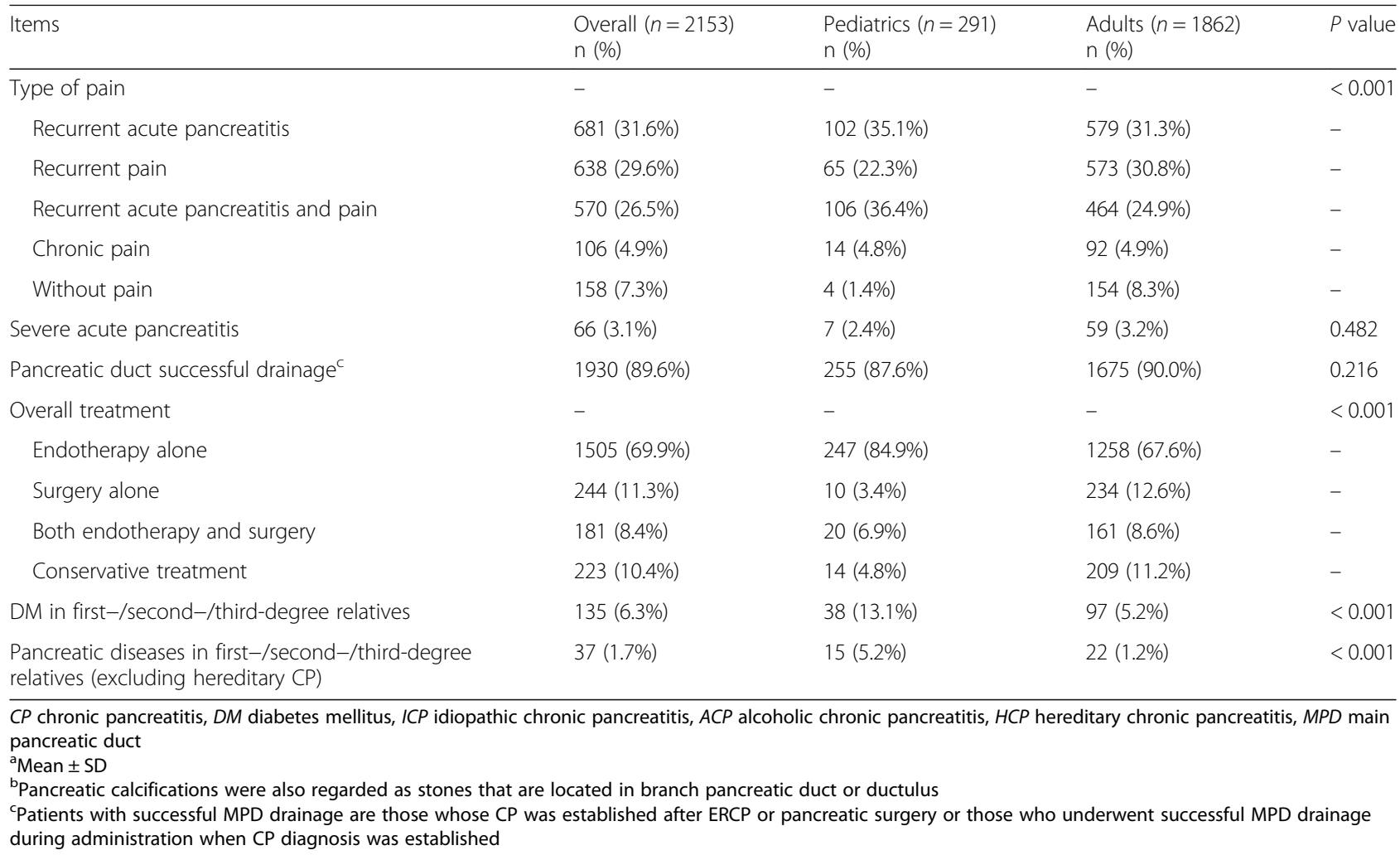

when patients feel unwell, all patients were checked regularly (at least once a year). Ultrasound, magnetic resonance imaging (MRI), or computed tomography (CT) examination was performed to assess the condition. Patients who did not return to our hospital were followed up by telephone and recorded in the database. The end point of the study was December 2013. In December 2013, we followed up all patients with CP in the database, with the exception of some lost visits and deaths [12]. Follow-up was defined from the onset of CP to the time of the last follow-up, death, or end of follow-up (December 2013), whichever came earliest.

The exclusion criteria for this study were as follows (Figure 1): CP patients diagnosed with pancreatic cancer within 2 years of CP diagnosis [24], grooved pancreatitis (GP) [25], and autoimmune pancreatitis (AIP). Patients were assigned into pediatric group (onset before 18 years of age) and adult group (onset after 18 years of age).

In the study of steatorrhea, patients with steatorrhea diagnosed before CP were excluded in both groups.

The CP database establishing was as mentioned in our previous study [12]. The study was approved by the Ethics Committee of Changhai Hospital. Written informed consent was obtained from all participating patients. All of the diagnostic and therapeutic modalities were carried out in accordance with the approved guidelines.

\section{Definitions}

The diagnosis of CP is based on the 2002 version of Asia Pacific consensus [26]. In the definition of etiologies, men with alcoholic intake of more than $80 \mathrm{~g} / \mathrm{d}$ or women with alcoholic intake of more than $60 \mathrm{~g} / \mathrm{d}$ for more than 2 years, excluding other causes, alcoholic CP could be diagnosed [27]. At least 2 first-degree relatives, or at least $3 \mathrm{~s}$-degree relatives with $\mathrm{CP}$ and/or recurrent $\mathrm{AP}$, excluding other causes, patients can be diagnosed as hereditary CP [28]. Patients with pancreatic divisum and abnormal pancreaticobiliary drainage are defined as abnormal anatomy of the pancreatic duct (although controversial) [29]. Patients with a clear history of pancreatic trauma and imaging findings suggesting secondary dilatation of the pancreatic duct may be diagnosed as traumatic CP. Hyperlipidemic CP was diagnosed in $\mathrm{CP}$ patients with plasma triglyceride $>1000 \mathrm{mg} / \mathrm{dL}$ [30]. When all the above causes are excluded, the patient can be diagnosed as idiopathic CP. The definition of severe acute pancreatitis (SAP) was based on the 1992 version of Atlanta classification [31].

Steatorrhea was diagnosed when one of the following two conditions was met: (1) stench, oily chronic diarrhea [32]; (2) positive result in quantification of fecal fat determination (fecal fat quantitation was performed within three days; patients with stool fat excretion over $14 \mathrm{~g} /$ day was diagnosed as steatorrhea). 
Table 2 Predictive factors for steatorrhea development in pediatric patients after the diagnosis of CP (256 cases)

\begin{tabular}{|c|c|c|c|c|c|}
\hline \multirow[t]{2}{*}{ Predictors } & \multirow[t]{2}{*}{ n (\%) } & \multicolumn{2}{|c|}{ Univariate Analysis } & \multicolumn{2}{|c|}{ Multivariate Analysis } \\
\hline & & $\mathrm{P}$ & HR $(95 \% \mathrm{Cl})$ & $\mathrm{P}$ & HR $(95 \% \mathrm{Cl})$ \\
\hline Gender (male) & $124(48.4 \%)$ & 0.411 & $0.353(0.029-4.233)$ & & \\
\hline Age at the onset of $C P, y^{a}$ & $\begin{array}{l}11.573 \pm \\
4.702\end{array}$ & 0.104 & $1.121(0.977-1.286)$ & 0.135 & \\
\hline Age at the diagnosis of $C P, y^{a}$ & $\begin{array}{l}18.141 \pm \\
6.762\end{array}$ & 0.235 & $0.880(0.712-1.087)$ & & \\
\hline Smoking history & $14(5.5 \%)$ & 0.510 & $4.355(0.055-346.356)$ & & \\
\hline Alcohol consumption & & 0.899 & & & \\
\hline $0 \mathrm{~g} / \mathrm{d}$ & $241(94.1 \%)$ & Contro & & & \\
\hline $0-20 \mathrm{~g} / \mathrm{d}$ & $5(2.0 \%)$ & 0.447 & $0.036(0.000-2.373 \mathrm{E} 3)$ & & \\
\hline $20-80 \mathrm{~g} / \mathrm{d}$ & $7(2.7 \%)$ & 0.716 & $0.043(0.000-1.029 \mathrm{E} 6)$ & & \\
\hline$>80 \mathrm{~g} / \mathrm{d}$ & $3(1.2 \%)$ & 0.735 & $0.042(0.000-3.846 \mathrm{E} 6)$ & & \\
\hline Body mass index ${ }^{a}$ & $\begin{array}{l}19.304 \pm \\
3.338\end{array}$ & 0.738 & $0.931(0.611-1.419)$ & & \\
\hline Etiology & & 0.579 & & & \\
\hline ICP & $220(85.9 \%)$ & Contro & & & \\
\hline ACP & $2(0.8 \%)$ & 0.710 & $2.081(0.043-99.757)$ & & \\
\hline Abnormal anatomy of pancreatic duct & $22(8.6 \%)$ & 0.690 & $2.271(0.040-127.502)$ & & \\
\hline $\mathrm{HCP}$ & $7(2.7 \%)$ & 0.912 & $1.375(0.005-401.007)$ & & \\
\hline Post-traumatic CP & $3(1.2 \%)$ & 1.000 & $1.008(0.000-2.361 \mathrm{E} 5)$ & & \\
\hline Hyperlipidemic CP & $2(0.8 \%)$ & 0.065 & $\begin{array}{l}208.297(0.719- \\
6.036 \mathrm{E} 4)\end{array}$ & & \\
\hline Initial manifestations & & 0.859 & & & \\
\hline Abdominal pain & $249(97.3 \%)$ & 0.978 & $\begin{array}{l}\text { 1.392E3 (0.000- } \\
9.416 \mathrm{E} 228)\end{array}$ & & \\
\hline Endocrine dysfunction & $5(2.0 \%)$ & 0.972 & $\begin{array}{l}1.175 E 4(0.000- \\
8.352 E 229)\end{array}$ & & \\
\hline Others & $2(0.8 \%)$ & & & & \\
\hline Pancreatic stones ${ }^{\mathrm{bc}}$ & $170(66.4 \%)$ & 0.582 & $1.540(0.331-7.173)$ & & \\
\hline Biliary stricture $^{b}$ & $9(3.5 \%)$ & 0.678 & $0.045(0.000-1.013 E 5)$ & & \\
\hline $\mathrm{DM}^{\mathrm{b}}$ & $8(3.1 \%)$ & 0.015 & $51.140(2.172-1.203 E 3)$ & 0.806 & \\
\hline Pancreatic pseudocyst ${ }^{\mathrm{b}}$ & $26(10.2 \%)$ & 0.762 & $1.389(0.165-11.705)$ & & \\
\hline Morphology of MPD & & 0.633 & & & \\
\hline Pancreatic stone alone & $82(32.0 \%)$ & 0.329 & $0.082(0.001-12.473)$ & & \\
\hline MPD stenosis alone & $52(20.3 \%)$ & 0.350 & $0.060(0.000-21.656)$ & & \\
\hline MPD stenosis and stone & $113(44.1 \%)$ & 0.584 & $0.229(0.001-44.967)$ & & \\
\hline Complex pathologic changes & $9(3.5 \%)$ & Contro & & & \\
\hline Type of pain ${ }^{b}$ & & 0.845 & & & \\
\hline Recurrent acute pancreatitis & $93(36.3 \%)$ & 0.571 & $0.218(0.001-42.016)$ & & \\
\hline Recurrent pain & $48(18.8 \%)$ & 0.950 & 1.167 (0.009-147.028) & & \\
\hline Recurrent acute pancreatitis and pain & $92(35.9 \%)$ & 0.854 & $0.637(0.005-78.045)$ & & \\
\hline Chronic pain & $10(3.9 \%)$ & 0.670 & $0.123(0.000-1.907 E 3)$ & & \\
\hline Without pain & $13(5.1 \%)$ & Contro & & & \\
\hline Severe acute pancreatitis ${ }^{b}$ & $7(2.7 \%)$ & 0.023 & $13.946(1.442-134.909)$ & 0.023 & $13.946(1.442-134.909)$ \\
\hline Pancreatic duct successful drainage ${ }^{\text {bd }}$ & $29(11.3 \%)$ & 0.904 & $0.774(0.012-50.413)$ & & \\
\hline Treatment strategy & & 0.873 & & & \\
\hline
\end{tabular}


Table 2 Predictive factors for steatorrhea development in pediatric patients after the diagnosis of CP (256 cases) (Continued)

\begin{tabular}{|c|c|c|c|c|c|}
\hline \multirow[t]{2}{*}{ Predictors } & \multirow[t]{2}{*}{ n (\%) } & \multicolumn{2}{|c|}{ Univariate Analysis } & \multicolumn{2}{|c|}{ Multivariate Analysis } \\
\hline & & $P$ & HR $(95 \% \mathrm{Cl})$ & $\mathrm{P}$ & $\mathrm{HR}(95 \% \mathrm{Cl})$ \\
\hline Endotherapy alone & $44(17.2 \%)$ & 0.876 & $0.739(0.017-32.985)$ & & \\
\hline Surgery alone & $11(4.3 \%)$ & 0.621 & $0.231(0.001-76.658)$ & & \\
\hline Both endotherapy and surgery & 0 & 0.904 & $0.774(0.012-51.413)$ & & \\
\hline Conservative treatment & $201(78.5 \%)$ & \multicolumn{2}{|c|}{ Control } & & \\
\hline DM in first-/second-/third-degree relatives & $29(11.3 \%)$ & 0.489 & $0.042(0.000-327.986)$ & & \\
\hline $\begin{array}{l}\text { Pancreatic diseases in first-/second-/third-degree relatives (excluding } \\
\text { hereditary (P) }\end{array}$ & $12(4.7 \%)$ & 0.572 & $0.278(0.003-23.531)$ & & \\
\hline
\end{tabular}

$C P$ chronic pancreatitis, DM diabetes mellitus, ICP idiopathic chronic pancreatitis, $A C P$ alcoholic chronic pancreatitis, $H C P$ hereditary chronic pancreatitis, $M P D$ main pancreatic duct, $H R$ hazard ratio, $\mathrm{Cl}$ confidence interval

${ }^{\mathrm{a}} \mathrm{Mean} \pm \mathrm{SD}$

${ }^{\mathrm{b}}$ Before or at the diagnosis of $\mathrm{CP}$

'Pancreatic calcifications were also regarded as stones that are located in branch pancreatic duct or ductulus

dPatients with successful MPD drainage are those whose CP was established after ERCP or pancreatic surgery or those who underwent successful MPD drainage during administration when $\mathrm{CP}$ diagnosis was established

\section{Treatment strategy}

Endoscopic interventional therapy was the first choice for CP patients. Extracorporeal shock wave lithotripsy (ESWL) and endoscopic retrograde cholangiopancreatography (ERCP) were used to remove pancreatic duct stones and drain the main pancreatic duct successfully $[15,33-36]$. The indications of surgery in $\mathrm{CP}$ patients include: endoscopic interventional therapy can not treat symptoms, combined with CBD stenosis but endoscopic treatment failed, cannot exclude malignant lesions or malignant diagnosed through biopsy, complex conditions and so on [37]. Surgical methods include surgical drainage, pancreaticoduodenectomy and distal pancreatectomy. In painless $\mathrm{CP}$ patients, endoscopic intervention or surgical treatment is indicated in patients with CBD stenosis or pancreatic portal hypertension [38].

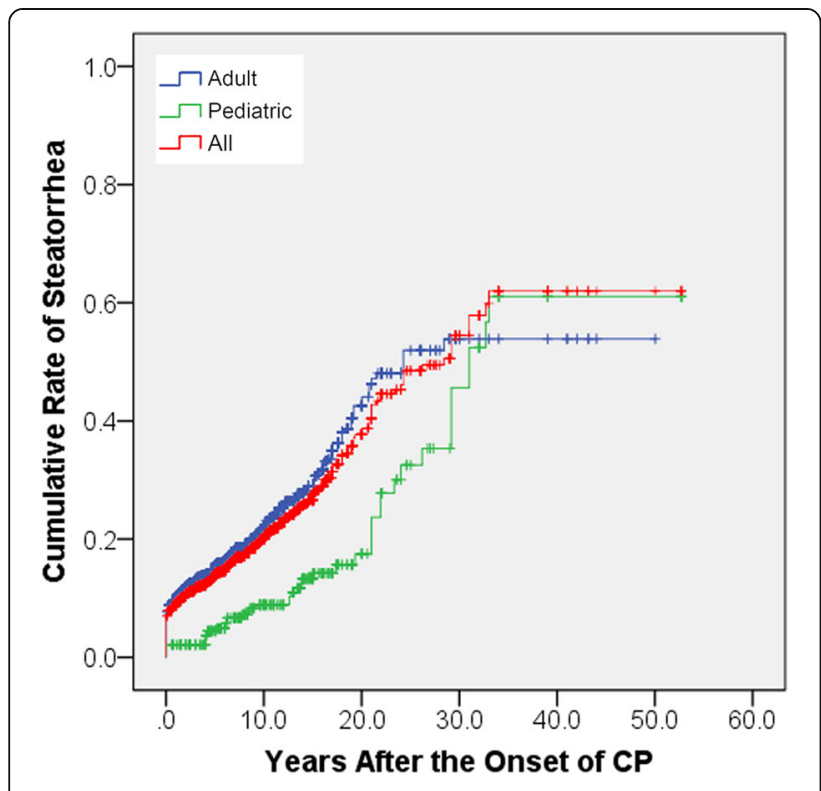

Fig. 2 The cumulative rates of steatorrhea after the onset of CP
Indications for endoscopic or surgical treatment did not include simple DM or steatorrhea. The treatment strategies of $\mathrm{CP}$ patients were as mentioned in our previous study [12].

\section{Statistical analysis}

In this study, continuous variables are represented in the form of mean \pm standard deviation (SD) and compared with an unpaired, 2-tailed $t$ test or the Mann-Whitney test. Categorical variables were expressed in the form of counting (percentage) and $X^{2}$ test or the Fisher exact test were used to compare. $\mathrm{CP}$ patients who onset before 18 years of age were assigned into pediatric group and after 18 years of age were assigned into adult groups. The cumulative rates of steatorrhea in both groups after the onset of CP were calculated by Kaplan-Meier method [39]. The statistical analysis were as mentioned in our previous study [12].

Patients who had steatorrhea at/before the diagnosis of $\mathrm{CP}$ in pediatric and adult groups were excluded respectively. SPSS (version 21.0) was used to calculate the significance of each variable by multivariate Cox regression analysis in both groups.

\section{Results}

\section{General characteristics of the subjects}

As shown in Figure 1, from January 2000 to December 2013, a total of 2287 CP patients were entered into the Changhai CP Database. After the exclusion of 134 patients, including 10 patients diagnosed with GP, 108 patients diagnosed with AIP, and 16 patients diagnosed with pancreatic cancer within 2 years after the diagnosis of CP, a cohort of 2153 patients with CP was established. The median duration of follow-up was 7.6 years (range $0.0-52.7$ years), with 10.4 years (range $0.0-52.7$ years) in the pediatrics and 7.0 years (range $0.0-50.0$ years) in the adults. 
Table 3 Predictive factors for steatorrhea development in adult patients after the diagnosis of CP (1600 cases)

\begin{tabular}{|c|c|c|c|c|c|}
\hline \multirow[t]{2}{*}{ Predictors } & \multirow[t]{2}{*}{ n (\%) } & \multicolumn{2}{|c|}{ Univariate Analysis } & \multicolumn{2}{|c|}{ Multivariate Analysis } \\
\hline & & $\bar{P}$ & $\mathrm{HR}(95 \% \mathrm{Cl})$ & $\mathrm{P}$ & $\mathrm{HR}(95 \% \mathrm{Cl})$ \\
\hline Gender (male) & $1161(72.6 \%)$ & $<0.001$ & $2.502(1.639-3.820)$ & $<0.001$ & $2.694(1.756-4.133)$ \\
\hline Age at the onset of $C P, y^{a}$ & $42.777 \pm 13.997$ & 0.429 & $0.996(0.984-1.007)$ & & \\
\hline Age at the diagnosis of $C P, y^{a}$ & $46.798 \pm 13.333$ & $<0.001$ & $0.972(0.961-0.984)$ & $<0.001$ & $0.966(0.953-0.978)$ \\
\hline Smoking history & $608(38.0 \%)$ & 0.188 & $1.222(0.907-1.645)$ & & \\
\hline Alcohol consumption & & 0.098 & & & \\
\hline $0 \mathrm{~g} / \mathrm{d}$ & $1000(62.5 \%)$ & Control & & & \\
\hline $0-20 \mathrm{~g} / \mathrm{d}$ & 49 (3.1\%) & 0.481 & $0.661(0.209-2.089)$ & & \\
\hline $20-80 \mathrm{~g} / \mathrm{d}$ & $202(12.6 \%)$ & 0.129 & $1.386(0.909-2.144)$ & & \\
\hline$>80 \mathrm{~g} / \mathrm{d}$ & $349(21.8 \%)$ & 0.036 & $1.437(1.024-2.016)$ & & \\
\hline Body mass index ${ }^{a}$ & $25.316 \pm 96.332$ & 0.882 & $0.996(0.942-1.052)$ & & \\
\hline Etiology & & 0.018 & & 0.143 & \\
\hline $\mathrm{ICP}$ & $1207(75.4 \%)$ & Control & & Control & \\
\hline $\mathrm{ACP}$ & $338(21.1 \%)$ & 0.037 & $1.414(1.021-1.956)$ & 0.219 & \\
\hline Abnormal anatomy of pancreatic duct & $30(1.9 \%)$ & 0.373 & $0.530(0.131-2.146)$ & 0.658 & \\
\hline $\mathrm{HCP}$ & $11(0.7 \%)$ & 0.962 & $0.000(0.000-3.933 \mathrm{E} 182)$ & 0.345 & \\
\hline Post-traumatic CP & $7(0.4 \%)$ & 0.003 & $8.514(2.088-34.720)$ & 0.041 & \\
\hline Hyperlipidemic CP & $7(0.4 \%)$ & 0.952 & $0.000(0.000-1.191 \mathrm{E} 142)$ & 0.178 & \\
\hline Initial manifestations & & $<0.001$ & & $<0.001$ & \\
\hline Abdominal pain & $1371(85.7 \%)$ & $<0.001$ & $0.401(0.253-0.636)$ & $<0.001$ & $0.308(0.192-0.494)$ \\
\hline Endocrine dysfunction & $104(6.5 \%)$ & 0.130 & $0.604(0.315-1.160)$ & 0.059 & $0.491(0.235-1.027)$ \\
\hline Others & $125(7.8 \%)$ & Control & & Control & \\
\hline Pancreatic stones ${ }^{\mathrm{bc}}$ & $1114(69.6 \%)$ & 0.830 & $0.966(0.701-1.330)$ & & \\
\hline Biliary stricture ${ }^{b}$ & $124(7.8 \%)$ & 0.097 & $1.512(0.928-2.463)$ & & \\
\hline $\mathrm{DM}^{\mathrm{b}}$ & $265(16.6 \%)$ & 0.031 & $1.450(1.034-2.035)$ & 0.029 & $1.558(1.047-2.319)$ \\
\hline Pancreatic pseudocyst ${ }^{\mathrm{b}}$ & $123(7.7 \%)$ & 0.355 & $1.284(0.756-2.180)$ & & \\
\hline Morphology of MPD & & 0.063 & & & \\
\hline Pancreatic stone alone & $394(24.6 \%)$ & 0.047 & $1.837(1.009-3.343)$ & & \\
\hline MPD stenosis alone & 495 (30.9\%) & 0.016 & $2.033(1.144-3.613)$ & & \\
\hline MPD stenosis and stone & $506(31.6 \%)$ & 0.194 & $1.483(0.818-2.687)$ & & \\
\hline Complex pathologic changes & $205(12.8 \%)$ & Control & & & \\
\hline Type of pain ${ }^{b}$ & & 0.086 & & & \\
\hline Recurrent acute pancreatitis & $472(29.5 \%)$ & 0.007 & $0.534(0.339-0.843)$ & & \\
\hline Recurrent pain & $438(27.4 \%)$ & 0.048 & $0.636(0.406-0.996)$ & & \\
\hline Recurrent acute pancreatitis and pain & $388(24.3 \%)$ & 0.021 & $0.578(0.364-0.919)$ & & \\
\hline Chronic pain & $62(3.9 \%)$ & 0.206 & $0.543(0.211-1.398)$ & & \\
\hline Without pain & $240(15.0 \%)$ & Control & & & \\
\hline Severe acute pancreatitis ${ }^{\mathrm{b}}$ & $50(3.1 \%)$ & 0.061 & $0.153(0.021-1.091)$ & & \\
\hline Pancreatic duct successful drainage ${ }^{\text {bd }}$ & $223(13.9 \%)$ & 0.987 & $1.004(0.648-1.555)$ & & \\
\hline Treatment strategy & & 0.698 & & & \\
\hline Endotherapy alone & $120(7.5 \%)$ & 0.657 & $0.871(0.472-1.607)$ & & \\
\hline Surgery alone & $87(5.4 \%)$ & 0.282 & $1.400(0.758-2.585)$ & & \\
\hline Both endotherapy and surgery & $14(0.9 \%)$ & 0.951 & $0.000(0.000-3.013 \mathrm{E} 148)$ & & \\
\hline Conservative treatment & $1379(86.2 \%)$ & Control & & & \\
\hline
\end{tabular}


Table 3 Predictive factors for steatorrhea development in adult patients after the diagnosis of CP (1600 cases) (Continued)

\begin{tabular}{|c|c|c|c|c|c|}
\hline \multirow[t]{2}{*}{ Predictors } & \multirow[t]{2}{*}{ n (\%) } & \multicolumn{2}{|c|}{ Univariate Analysis } & \multicolumn{2}{|c|}{ Multivariate Analysis } \\
\hline & & P & $\mathrm{HR}(95 \% \mathrm{Cl})$ & $\mathrm{P}$ & $\mathrm{HR}(95 \% \mathrm{Cl})$ \\
\hline DM in first-/second-/third-degree relatives & $76(4.8 \%)$ & 0.241 & $0.587(0.241-1.429)$ & & \\
\hline $\begin{array}{l}\text { Pancreatic diseases in first-/second-/third-degree } \\
\text { relatives (excluding hereditary CP) }\end{array}$ & $16(1.0 \%)$ & 0.691 & $0.671(0.094-4.793)$ & & \\
\hline \multicolumn{6}{|c|}{$\begin{array}{l}C P \text { chronic pancreatitis, } D M \text { diabetes mellitus, ICP idiopathic chronic pancreatitis, } A C P \text { alcoholic chronic pancreatitis, HCP hereditary chronic pancreatitis, MPD mair } \\
\text { pancreatic duct, } H R \text { hazard ratio, } C I \text { confidence interval } \\
\text { a Mean } \pm \text { SD } \\
\text { b Before or at the diagnosis of } C P \\
\text { cPancreatic calcifications were also regarded as stones that are located in branch pancreatic duct or ductulus } \\
\text { dPatients with successful MPD drainage are those whose CP was established after ERCP or pancreatic surgery or those who underwent successful MPD drainage } \\
\text { during administration when CP diagnosis was established }\end{array}$} \\
\hline
\end{tabular}

The general characteristics of the patients with $\mathrm{CP}$ are presented in Table 1. The mean age at the onset and the diagnosis of $\mathrm{CP}$ were 11.622 and 19.727, respectively. The male-to-female ratio in pediatrics was approximately 1:1, while in adults was $3: 1$. Patients with smoking or drinking history were significantly less in pediatrics (both $P<0.001$ ). DM, steatorrhea, pancreatic pseudocyst, and biliary stricture were significantly common in adults (all $P<0.05$ ). The etiology and type of pain were also significantly different between the pediatric and the adult groups (both $P<0.001$ ).

\section{Cumulative rates of steatorrhea}

Steatorrhea was found in 22.9\% (493/2153) of patients after the onset of CP. The proportions were 15.8\% (46/ $291)$ in pediatric patients and $24.0 \%(447 / 1862)$ in adult patients. The cumulative proportions of steatorrhea in pediatric patients were $2.1 \%$ (95\% confidence interval [CI], $0.5-3.7 \%), 4.1 \%$ (95\% CI, 1.6-6.6\%) and 7.2\% (95\% $\mathrm{CI}, 3.5 \%-10.9)$ at 3,5 and 10 years after the diagnosis of $\mathrm{CP}$, respectively. The cumulative proportions of steatorrhea in adult patients were $12.8 \%$ (95\% CI, $11.2-14.4 \%$ ), $14.6 \%$ (95\% CI, $12.8-16.4 \%$ ) and $18.3 \%$ (95\% CI, 16.1$20.5 \%)$ at 3,5 and 10 years after the diagnosis of CP, respectively. Pediatric and adult patients showed significant difference in the rate of steatorrhea $(P=0.002$, Figure 2).

\section{Predictors for steatorrhea development in pediatric patients}

After the exclusion of 35 patients diagnosed with steatorrhea before the diagnosis of $\mathrm{CP}$ in the pediatric patients, a total of 256 patients with CP were finally enrolled in the pediatric group. A univariate analysis for steatorrhea development among the 256 pediatric patients included in the study is shown in Table 2. Three variables showed a $P$ value of less than 0.15 : age at the onset of CP, DM, and SAP.

For the multivariate analysis, the 3 predictors above were included in the Cox proportional hazards regression model. Finally, 1 predictor for steatorrhea development in pediatric patients was identified. The risk of developing steatorrhea was significantly higher in pediatric patients with a history of SAP before the diagnosis of CP (Hazard ratio [HR], 13.946, 95\% CI, 1.442134.909).

\section{Predictors for steatorrhea development in adult patients} After the exclusion of 262 patients diagnosed with steatorrhea before the diagnosis of $\mathrm{CP}$ in the adult patients, a total of 1600 patients with CP were finally enrolled in the adult group. A univariate analysis for steatorrhea development among the 1600 adult patients included in the study is shown in Table 3 . Five variables showed a $P$ value of less than 0.05: gender, age at the diagnosis of $\mathrm{CP}$, etiology, initial manifestations, and DM.

For the multivariate analysis, the 5 predictors above were included in the Cox proportional hazards regression model. Finally, 4 predictors for steatorrhea development in adult patients were identified. The risk of developing steatorrhea was significantly higher in male patients (HR, 2.694, 95\% CI, 1.756-4.133) and patients with a history of DM before the diagnosis of CP (HR, 1.558, 95\% CI, 1.047-2.319). Adult patients with an older age at the diagnosis of CP (HR, 0.966, 95\% CI, 0.953-0.978) were associated with decreased risk of developing steatorrhea. Initial manifestations were also identified risk factors for steatorrhea development in adult patients.

\section{Discussion}

We focused on CP in pediatrics in the present study. Presence of steatorrhea was set as the sign of severe PEI. To our knowledge, this is the first study to analyze the risk factors of steatorrhea in pediatric patients with CP.

In the present study, $15.8 \%$ (46/291) of pediatric patients with CP developed steatorrhea, and 24.0\% (447/ 1862) of adult patients developed steatorrhea. A previous study showed that exocrine and endocrine insufficiency developed more slowly in early-onset $\mathrm{CP}$ than in late-onset CP [40]. This could be due to a better preservation of pancreatic function and better repair capacity 
after injury in pediatric CP patients. However, after a long term of follow-up for more than 30 years, the cumulative rate of steatorrhea in pediatrics was similar or even higher than in adults (Figure 2). Therefore, pediatric $\mathrm{CP}$ patients had a reduced risk of steatorrhea compared to adult $\mathrm{CP}$ patients in the early period of $\mathrm{CP}$ course, but the risk increased with longer-term of follow-up.

In the risk factor analysis, a history of SAP before the diagnosis of $\mathrm{CP}$ was identified significantly associated with steatorrhea development in pediatric CP patients. It is not exactly the same as risk factors in adult patients. In adult $\mathrm{CP}$ patients, genders, age at the diagnosis of $\mathrm{CP}$, initial manifestations, and DM before the diagnosis of $\mathrm{CP}$ were identified risk factors for steatorrhea development. In the previous study, male gender, adults, DM, alcohol abuse and pancreaticoduodenectomy were identified risk factors for steatorrhea development in the general population [12], which are similar with the adult group in the present study.

The risk factor analysis of steatorrhea may help in the early diagnosis of PEI in pediatric patients. Pediatric $\mathrm{CP}$ patients with PEI suffer from decreased dietary intake and malabsorption. The malnutrition caused by PEI may retard their growth and development, even result in failure to thrive in these children. This may cause incredible suffering for the children and families who live with them [41]. However, steatorrhea and associated symptoms are not evident until duodenal lipase falls below 5$10 \%$ of normal postprandial levels [42]. Thus, PEI may have occurred even the children have no symptoms of steatorrhea. This study provided a relatively accurate risk factor analysis. Age at the onset of CP, DM and SAP were identified the risk factors for steatorrhea in pediatric CP patients. Therefore, these pediatric patient groups were suggested to be closely monitored.

These high-risk populations in pediatric $\mathrm{CP}$ patients may benefit from a full adequate PERT. Although PERT was recommended in all pediatric CP patients [13], closely follow-up and dosage adjustment was quite important for these high-risk populations. It can deliver sufficient enzymatic activity into the duodenal lumen simultaneously with the meal, in order to optimize digestion and absorption of nutrients. The PERT will improve the nutritional status for these children and help with their growth and development. This may help in the early treatment of PEI in pediatric patients and reduce the adverse events caused by PEI.

Our study has some limitations. First, clinical steatorrhea was a sign of severe PEI, regardless of dietary habits and steatorrhea associated with abdominal diseases. Second, data was retrospectively collected from 2000 to 2004, which may introduce a recall bias. However, statistical analysis showed that there was no significant difference in clinical characteristics between patients before and after January 2005. In this sense, the recall bias has the least impact on the results. Third, risk factors analysis did not include all potential factors associated with the development of steatorrhea. Fourth, 603 patients with $\mathrm{CP}$ were followed up for less than 2 years, which may introduce a misdiagnosis bias between $\mathrm{CP}$ and pancreatic cancer.

\section{Conclusions}

In conclusion, steatorrhea is extremely harmful for children. Age at the onset of CP. DM and SAP were identified risk factors for the development of steatorrhea in pediatric CP patients. Therefore, it is suggested that pediatric patients in these high-risk groups be closely followed and examined. They may benefit from adequate PERT.

\begin{abstract}
Abbreviations
AIP: Autoimmune pancreatitis; Cl: Confidence interval; CP: Chronic pancreatitis; CT: Computed tomography; DM: Diabetes mellitus; ERCP: Endoscopic retrograde cholangiopancreatography;

ESWL: Extracorporeal shockwave lithotripsy; GP: Groove pancreatitis; HR: Hazard ratio; MRI: Magnetic resonance imaging; PEI: Pancreatic enzyme insufficiency; PERT: Pancreatic exocrine replacement therapy; SAP: Severe acute pancreatitis; SD: Standard deviation
\end{abstract}

\section{Acknowledgements}

Not applicable.

\section{Authors' contributors}

L Hao, TW and L He participated in the acquisition, analysis, and interpretation of data, as well as in the manuscript drafting. YWB, DZ, XPZ, LX, JP, DW, JTJ, TTD, JHL, LSW, WBZ, HC, TX, HLG, BRL and ZL participated in data acquisition and manuscript drafting. LHH, ZSL and ZLX contributed to the conception, design, and data interpretation, as well as revised the manuscript for important intellectual content. BRL, LHH, LX, and LSW provided the funding to this study. All authors read and approved the final manuscript. All authors have read and approved the manuscript, and ensure that this is the case.

\section{Funding}

This study was supported by the National Natural Science Foundation of China [Grant Nos. 81500490 (BRL), 81770635 (LHH), 81470883 (LHH) and 81770632(LX)] and Three engineering training funds in Shenzhen [Grant No. SYJY201713(LSW)] in data acquisition and manuscript drafting, Shanghai Rising-Star Program [Grant No. 17QA1405500 (LHH)], Shanghai Outstanding Youth Doctor Training Program [Grant No. AB83030002015034 (LHH)], and Shanghai Youth Top-notch Talent Program [Grant No. HZW2016FZ67 (LHH)], in conception design, data interpretation, and manuscript revise.

\section{Availability of data and materials}

The datasets used and/or analyzed during the current study are available from the corresponding author on reasonable request.

\section{Ethics approval and consent to participate}

The study was approved by the Ethics Committee of Changhai Hospital. Written informed consent was obtained from all participating patients. Consent to participate for patients under 16 years old was provided by a parent or legal guardian.

Consent for publication

Not applicable.

Competing interests

The authors declare that they have no competing interests. 


\section{Publisher's Note}

Springer Nature remains neutral with regard to jurisdictional claims in published maps and institutional affiliations.

\section{Author details \\ ${ }^{1}$ Department of Gastroenterology, Hainan Branch of Chinese PLA General Hospital, Hainan, China. 'Department of Gastroenterology, Gongli Hospital, The Second Military Medical University, Shanghai, China. ${ }^{3}$ Department of Gastroenterology, Changhai Hospital, The Second Military Medical University, Shanghai, China. ${ }^{4}$ Department of Gastroenterology, The Second Clinical Medical College (Shenzhen People's Hospital), Jinan University, Guangdong, China. ${ }^{5}$ Department of Gastroenterology, Zhongda Hospital, Southeast University, Nanjing, China. ${ }^{6}$ Department of Gastroenterology, Air Force General Hospital, Beijing, China.}

Received: 18 October 2017 Accepted: 31 October 2018

Published online: 05 December 2018

\section{References}

1. Yadav D, Timmons L, Benson JT, Dierkhising RA, Chari ST. Incidence, prevalence, and survival of chronic pancreatitis: a population-based study. Am J Gastroenterol. 2011;106:2192-9.

2. Spanier B, Bruno MJ, Dijkgraaf MG. Incidence and mortality of acute and chronic pancreatitis in the Netherlands: a nationwide record-linked cohort study for the years 1995-2005. World J Gastroenterol. 2013;19:3018-26.

3. Hirota M, Shimosegawa T, Masamune A, Kikuta K, Kume K, Hamada S, Kihara Y, Satoh A, Kimura K, Tsuji I, Kuriyama S. The sixth nationwide epidemiological survey of chronic pancreatitis in Japan. Pancreatology. 2012;12:79-84

4. Braganza JM, Lee SH, McCloy RF, McMahon MJ. Chronic pancreatitis. Lancet. 2011:377:1184-97.

5. Dominguez-Munoz JE, Iglesias-Garcia J, Vilarino-Insua M, Iglesias-Rey M. 13C mixed triglyceride breath test to assess oral enzyme substitution therapy in patients with chronic pancreatitis. Clin Gastroenterol Hepatol. 2007:5:484-8.

6. Dominguez-Munoz JE, Iglesias-Garcia J. Oral pancreatic enzyme substitution therapy in chronic pancreatitis: is clinical response an appropriate marker for evaluation of therapeutic efficacy? JOP. 2010;11:158-62.

7. Pongprasobchai S. Maldigestion from pancreatic exocrine insufficiency. J Gastroenterol Hepatol. 2013:28(Suppl 4):99-102.

8. Montalto G, Soresi M, Carroccio A, Scafidi E, Barbagallo CM, Ippolito S, Notarbartolo A. Lipoproteins and chronic pancreatitis. Pancreas. 1994;9:137-8.

9. Tignor AS, Wu BU, Whitlock TL, Lopez R, Repas K, Banks PA, Conwell D. High prevalence of low-trauma fracture in chronic pancreatitis. Am J Gastroenterol. 2010;105:2680-6.

10. Wang D, Bi Y-W, Ji J-T, Xin L, Pan J, Liao Z, Du T-T, Lin J-H, Zhang D, Zeng $X-P$, et al. Extracorporeal shock wave lithotripsy is safe and effective for pediatric patients with chronic pancreatitis. Endoscopy. 2017:49:447-55.

11. Schwarzenberg SJ, Bellin M, Husain SZ, Ahuja M, Barth B, Davis H, Durie PR, Fishman DS, Freedman SD, Gariepy CE, et al. Pediatric chronic pancreatitis is associated with genetic risk factors and substantial disease burden. J Pediatr. 2015;166:890-6 e891.

12. Li BR, Pan J, Du TT, Liao Z, Ye B, Zou WB, Chen H, Ji JT, Zheng ZH, Wang D, et al. Risk factors for steatorrhea in chronic pancreatitis: a cohort of 2,153 patients. Sci Rep. 2016:6:21381.

13. Toouli J, Biankin AV, Oliver MR, Pearce CB, Wilson JS, Wray NH, Australasian Pancreatic C. Management of pancreatic exocrine insufficiency: Australasian pancreatic Club recommendations. Med J Aust. 2010;193:461-7.

14. Wang W, Liao Z, Li ZS, Shi XG, Wang LW, Liu F, Wu RP, Zheng JM. Chronic pancreatitis in Chinese children: etiology, clinical presentation and imaging diagnosis. J Gastroenterol Hepatol. 2009;24:1862-8.

15. Li ZS, Wang W, Liao Z, Zou DW, Jin ZD, Chen J, Wu RP, Liu F, Wang LW, Shi $X G$, et al. A long-term follow-up study on endoscopic management of children and adolescents with chronic pancreatitis. Am J Gastroenterol. 2010;105:1884-92.

16. Wang W, Liao Z, Li G, Li ZS, Chen J, Zhan XB, Wang LW, Liu F, Hu LH, Guo $Y$, et al. Incidence of pancreatic cancer in chinese patients with chronic pancreatitis. Pancreatology. 2011;11:16-23.

17. Wang W, Guo Y, Liao Z, Zou DW, Jin ZD, Zou DJ, Jin G, Hu XG, Li ZS Occurrence of and risk factors for diabetes mellitus in Chinese patients with chronic pancreatitis. Pancreas. 2011;40:206-12.
18. Xin L, He YX, Zhu XF, Zhang QH, Hu LH, Zou DW, Jin ZD, Chang XJ, Zheng JM, Zuo CJ, et al. Diagnosis and treatment of autoimmune pancreatitis: experience with 100 patients. Hepatobiliary Pancreat Dis Int. 2014;13:642-8.

19. Pan J, Xin L, Wang D, Liao Z, Lin JH, Li BR, Du TT, Ye B, Zou WB, Chen H, et al. Risk factors for diabetes mellitus in chronic pancreatitis: a cohort of 2011 patients. Medicine (Baltimore). 2016:95:e3251.

20. Yang YG, Hu LH, Chen H, Li B, Fan XH, Li JB, Wang JF, Deng XM. Targetcontrolled infusion of remifentanil with or without flurbiprofen axetil in sedation for extracorporeal shock wave lithotripsy of pancreatic stones: a prospective, open-label, randomized controlled trial. BMC Anesthesiol. 2015;15:161.

21. Hao L, Pan J, Wang D, Bi YW, Ji JT, Xin L, Liao Z, Du TT, Lin JH, Zhang D, et al. Risk factors and nomogram for pancreatic pseudocysts in chronic pancreatitis: a cohort of 1998 patients. J Gastroenterol Hepatol. 2017:32:1403-11.

22. Hao L, Bi YW, Zhang D, Zeng XP, Xin L, Pan J, Wang D, Ji JT, Du TT,Lin JH, et al. Risk factors and nomogram for common bile duct stricture inchronic pancreatitis: a cohort of 2153 patients. J ClinGastroenterol. 2017. https://doi. org/10.1097/MCG.0000000000000930.

23. Hao L, Zeng XP, Xin L, Wang D, Pan J, Bi YW, Ji JT, Du TT, Lin JH, Zhang D, et al. Incidence of and risk factors for pancreatic cancer in chronic pancreatitis: a cohort of 1656 patients. Dig Liver Dis. 2017;49(11):1249-56.

24. Li BR, Hu LH, Li ZS. Chronic pancreatitis and pancreatic cancer. Gastroenterology. 2014;147:541-2.

25. Malde DJ, Oliveira-Cunha M, Smith AM. Pancreatic carcinoma masquerading as groove pancreatitis: case report and review of literature. Jop. 2011;12 598-602.

26. Tandon RK, Sato N, Garg PK. Chronic pancreatitis: Asia-Pacific consensus report. J Gastroenterol Hepatol. 2002;17:508-18.

27. Witt H, Sahin-Toth M, Landt O, Chen JM, Kahne T, Drenth JP, Kukor Z, Szepessy E, Halangk W, Dahm S, et al. A degradation-sensitive anionic trypsinogen (PRSS2) variant protects against chronic pancreatitis. Nat Genet. 2006;38:668-73

28. Howes N, Lerch MM, Greenhalf W, Stocken DD, Ellis I, Simon P, Truninger K, Ammann R, Cavallini G, Charnley RM, et al. Clinical and genetic characteristics of hereditary pancreatitis in Europe. Clin Gastroenterol Hepatol. 2004;2:252-61.

29. Lu WF. ERCP and CT diagnosis of pancreas divisum and its relation to etiology of chronic pancreatitis. World J Gastroenterol. 1998;4:150-2.

30. Yadav D, Pitchumoni CS. Issues in hyperlipidemic pancreatitis. J Clin Gastroenterol. 2003;36:54-62.

31. Bradley EL, 3rd: A clinically based classification system for acute pancreatitis Summary of the international symposium on acute pancreatitis, Atlanta, Ga, September 11 through 13, 1992. Arch Surg 1993, 128:586-590.

32. Affronti J. Chronic pancreatitis and exocrine insufficiency. Prim Care. 2011; 38:515-37 ix

33. Li BR, Liao Z, Du TT, Ye B, Zou WB, Chen H, Ji JT, Zheng ZH, Hao JF, Jiang $Y Y$, et al. Risk factors for complications of pancreatic extracorporeal shock wave lithotripsy. Endoscopy. 2014;46:1092-100.

34. Sun XT, Hu LH, Xia T, Shi LL, Sun C, Du YQ, Wang W, Chen JM, Liao Z, Li ZS. Clinical features and endoscopic treatment of Chinese patients with hereditary pancreatitis. Pancreas. 2015;44:59-63.

35. Dumonceau JM, Delhaye M, Tringali A, Dominguez-Munoz JE, Poley JW, Arvanitaki M, Costamagna G, Costea F, Deviere J, Eisendrath P, et al. Endoscopic treatment of chronic pancreatitis: European Society of Gastrointestinal Endoscopy (ESGE) clinical guideline. Endoscopy. 2012:44:784-800.

36. Li BR, Liao Z, Du TT, Ye B, Chen H, Ji JT, Zheng ZH, Hao JF, Ning SB, Wang $D$, et al. Extracorporeal shock wave lithotripsy is a safe and effective treatment for pancreatic stones coexisting with pancreatic pseudocysts. Gastrointest Endosc. 2016;84:69-78.

37. Schreyer AG, Jung M, Riemann JF, Niessen C, Pregler B, Grenacher L, Hoffmeister A. S3 guideline for chronic pancreatitis - diagnosis, classification and therapy for the radiologist. Rofo. 2014;186:1002-8.

38. Ito T, Ishiguro H, Ohara H, Kamisawa T, Sakagami J, Sata N, Takeyama Y, Hirota M, Miyakawa $\mathrm{H}$, lgarashi $\mathrm{H}$, et al. Evidence-based clinical practice guidelines for chronic pancreatitis 2015. J Gastroenterol. 2016:51:85-92.

39. Ma Y, Zhou W, He S, Xu W, Xiao J. Tyrosine kinase inhibitor sunitinib therapy is effective in the treatment of bone metastasis from cancer of unknown primary: identification of clinical and immunohistochemical biomarkers predicting survival. Int J Cancer. 2016:139:1423-30.

40. Layer P, Yamamoto H, Kalthoff L, Clain JE, Bakken L, DiMagno EP. The different courses of early- and late-onset idiopathic and alcoholic chronic pancreatitis. Gastroenterology. 1994;107:1481-7. 
41. Perito ER, Rhee $S$. Relief for young children with severe chronic pancreatitis. J Pediatr Gastroenterol Nutr. 2017:64:338-9.

42. Smith RC, Smith SF, Wilson J, Pearce C, Wray N, Vo R, Chen J, Ooi CY, Oliver $M$, Katz T, et al. Summary and recommendations from the Australasian guidelines for the management of pancreatic exocrine insufficiency. Pancreatology. 2016;16:164-80

Ready to submit your research? Choose BMC and benefit from:

- fast, convenient online submission

- thorough peer review by experienced researchers in your field

- rapid publication on acceptance

- support for research data, including large and complex data types

- gold Open Access which fosters wider collaboration and increased citations

- maximum visibility for your research: over $100 \mathrm{M}$ website views per year

At $\mathrm{BMC}$, research is always in progress.

Learn more biomedcentral.com/submissions 